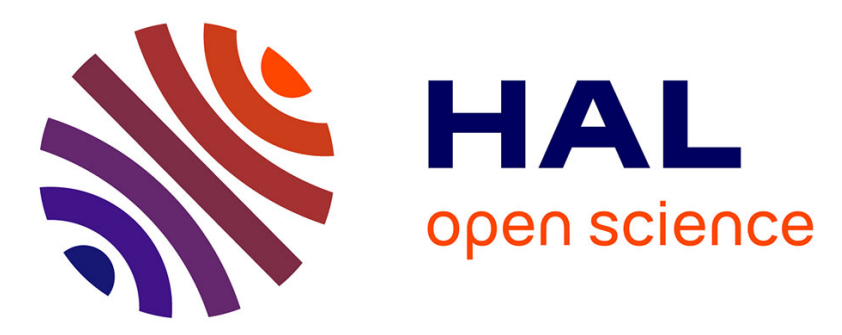

\title{
Evaluation Technique for The Failure Life Scatter of Lead-Free Solder Joints in Electronic Device
}

\author{
H. Miyauchi, Qiang Yu, T. Shibutani, M. Shiratori
}

\section{To cite this version:}

H. Miyauchi, Qiang Yu, T. Shibutani, M. Shiratori. Evaluation Technique for The Failure Life Scatter of Lead-Free Solder Joints in Electronic Device. THERMINIC 2007, Sep 2007, Budapest, Hungary. pp.32-37. hal-00202530

\section{HAL Id: hal-00202530 \\ https://hal.science/hal-00202530}

Submitted on 7 Jan 2008

HAL is a multi-disciplinary open access archive for the deposit and dissemination of scientific research documents, whether they are published or not. The documents may come from teaching and research institutions in France or abroad, or from public or private research centers.
L'archive ouverte pluridisciplinaire HAL, est destinée au dépôt et à la diffusion de documents scientifiques de niveau recherche, publiés ou non, émanant des établissements d'enseignement et de recherche français ou étrangers, des laboratoires publics ou privés. 


\title{
Evaluation Technique for The Failure Life Scatter of Lead-Free Solder Joints in Electronic Device
}

\author{
Hiroki MIYAUCHI*, Qiang YU*, Tadahiro SHIBUTANI*, \\ Masaki SHIRATORI* \\ *Department of Mechanical Engineering and Materials Science \\ Yokohama National University \\ 79-5, Tokiwadai, Hodogaya-ku, 240-8501, Japan \\ Phone: $+81-45-339-3862$ \\ Fax: $+81-45-331-6593$ \\ Email: miya@swan.me.ynu.ac.jp
}

\begin{abstract}
Recently, the electronic device equipments using a lot of semiconductors are widespread to all industrial fields. Solder joints are used to mount the electronic chips, such as ceramic resistors and capacitors, on the printed-circuit boards in almost all electronic devices. However, since in many cases the thermal expansion coefficients of electronic parts and PCBs have mismatch, cyclic thermal stress and strain causes solder fatigue. Especially in the power electronic module and car electric module, the evaluation of thermal fatigue life for the chip components is important. It is understood that the fatigue lives of some electronic devices show big scatter in the thermal cycle test, even if their design is the same. The dispersion of main design factors of solder joints is thought as one of these reasons. Moreover, the influence of the dispersion grows when the lead-free solder materials are used in the devices. Therefore, it cannot be bypassed as the main issue for the reliability evaluation in the solder joints. In this study, how the dispersion of design factors and the interacting effect between the design factors influences the failure life in lead-free solder joint was investigated by the analytical approach. Sensitivity analyses were carried out to study the main effect of the dispersion of each factor on solder joints. And then, the interacting effect between the factors on the reliability was studied by considering the structural asymmetry due to the unbalanced solder joints. As a result, a practical evaluating technique for the failure life scatter of solder joints was proposed.
\end{abstract}

\section{INTRODUCTION}

In recent years, the development of the semiconductor industry is remarkable and the electronic device equipment using a semiconductor is widespread to all industrial fields along with it. Solder is used to mount electronic parts, such as resistors and capacitors, on the printed-circuit boards in almost all electronic devices. However, since in many cases the thermal expansion coefficients of electronic parts and PCBs have mismatch, cyclic thermal stress and strain causes solder fatigue and device failure. Therefore, thermal fatigue life is important for electronic components.

The thermal fatigue life in solder joints can be evaluated by carrying out the thermal cycle test, mechanical shear fatigue test and the FEM analysis [1-4]. Until now, the fatigue life in solder joint has been chiefly evaluated based on the crack initiation. However, it is demanded to evaluate the final failure life of electronic components. So, it is necessary to evaluate not only crack initiation but also crack propagation process $[5,6]$. The former can be evaluated on the basis of Manson-Coffin's law [7]. In this study, a crack propagation analysis is carried out by using commercial FEM code Marc with user subroutine and the number of cycle to failure with crack propagation is evaluated using Miner's rule and Manson-Coffin's law [8].

It is understood that the failure lives of some electronic devices show large scatter in the thermal cycle test, even if their design is the same. The dispersion of main design factors such as material properties and geometric parameters of solder joints is thought as one of these reasons. It is very difficult to control the dispersion more than a present manufacturing process. At the same time, the changeover from eutectic $\mathrm{Sn}-\mathrm{Pb}$ solder to lead-free solder $(\mathrm{Sn}-\mathrm{Ag}-\mathrm{Cu})$ has been driven by environmental concerns [9]. The influence of the dispersion grows when a lead-free solder material is used in the devices. Therefore, it cannot be bypassed as the main issue for the reliability evaluation in the solder joints. In this study, how the dispersion of design factors influences the fatigue life in lead-free solder joint is investigated by the analytical approach. At first, sensitivity analyses are carried out to study the main effect of the dispersion of each factor on solder joints [10]. And then, the interacting effect between the factors on the reliability is studied by considering the structural asymmetry due to the unbalanced solder joints.

\section{NOMENCLATURE}

FEM Finite Element Method

PCB Printed Circuit Board

CTE Coefficient of Thermal Expansion

DOE Design of Experiment

$\Delta \varepsilon_{i n} \quad$ Total equivalent inelastic strain range

$\eta \quad$ Damage rate

$N_{f} \quad$ Number of cycles to fatigue 


\section{FAtigue CRACK PROPAGATION ANALYSIS}

Budapest, Hungary, 17-19 September 2007

The crack propagation can be evaluated by using one set of analytical model with the different proper crack size, which can be prepared beforehand. However, the direction of the crack propagation should be already known for this technique. Moreover, it is necessary to make a lot of models to express crack propagation process, and a huge amount of time and work are required for it. Therefore, the easier technique with more practicality is needed. In this section, the method of fatigue crack propagation analysis using a user subroutine for the commercial FEM code Marc is described. Fig. 1 shows the flow chart of fatigue crack propagation analysis. The elements whose cumulative damage by thermal fatigue high-ranked are deleted automatically by using a user subroutine. The cumulative damage for each element is obtained from total equivalent inelastic strain range. As a result, the process of natural crack propagation can be expressed even if the direction of the crack propagation is not understood.

Fig. 2 shows the results of fatigue crack propagation analysis for a 3216 chip model. The crack initiates from the edge of the solder layer between the chip electrode and the PCB, and then propagates along the solder area under the chip. After the crack passes through the whole area under the electrode, it starts to propagate along the fillet. In this case, solder joint under the electrode is broken completely by 9 steps analysis, and the equivalent strain results in 9 models as shown in Fig. 2 can be used to assess the fatigue life between each step (each model). To increase the assessment quantity, the equivalent inelastic strain range at the line shown in Fig. 3, is extracted for every model with an interval of $50 \mu \mathrm{m}$ crack propagation by interpolating the results of the models with rough interval shown in Fig. 2. By using linear interpolation method for these results, the total equivalent inelastic strain range in each crack propagation model is obtained as shown in Fig. 4. Based upon this result, the life cycle when solder joint is broken completely is calculated using Manson-Coffin's law and Miner's rule.

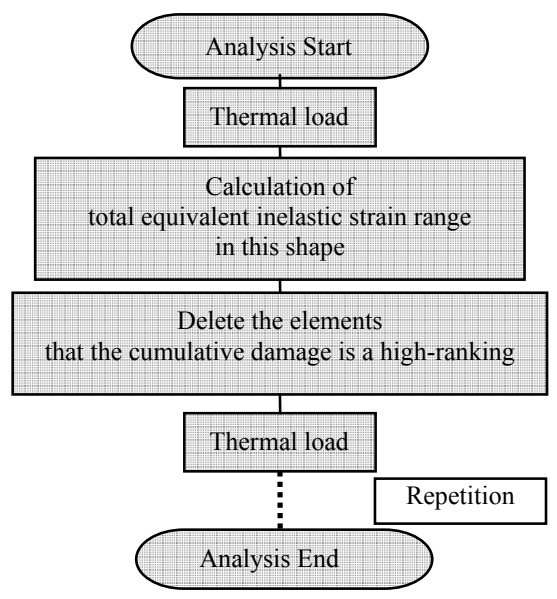

Fig. 1 Flow chart of fatigue crack propagation analysis
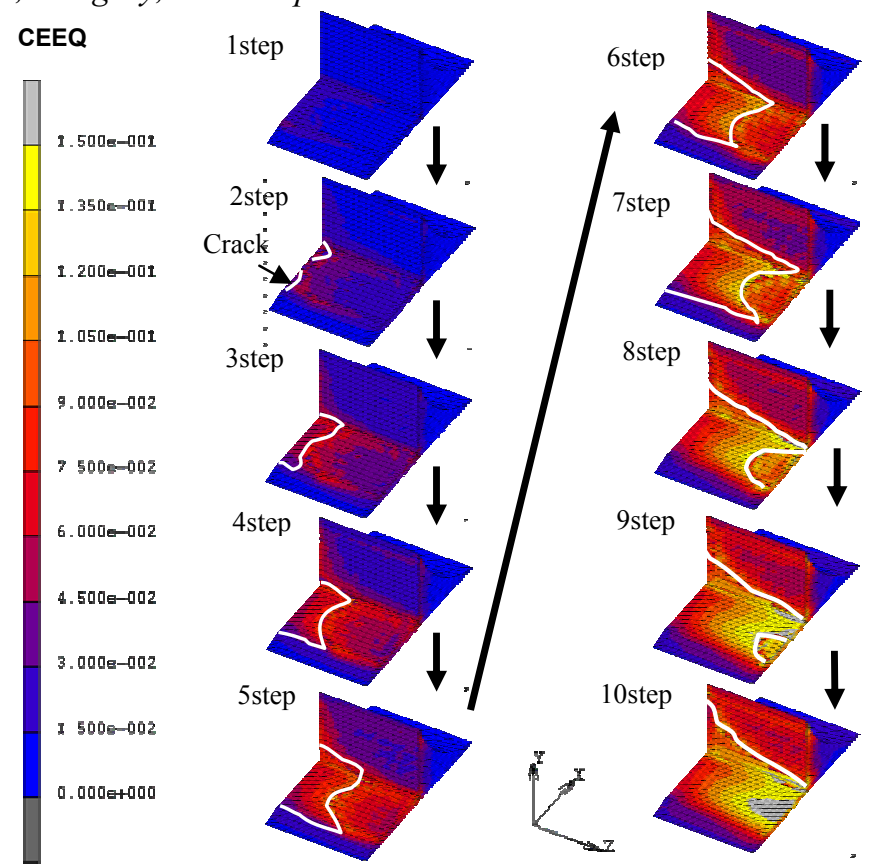

Fig. 2 Results of fatigue crack propagation analysis for a 3216 chip model

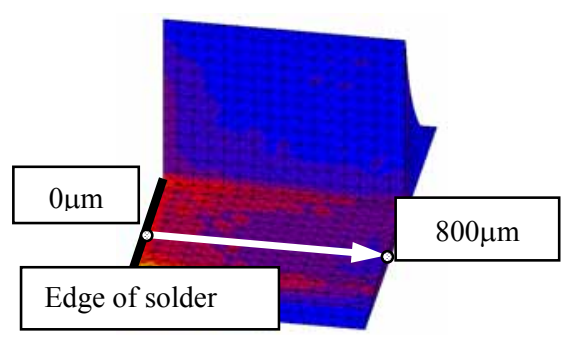

Fig. 3 Extraction line of inelastic strain range

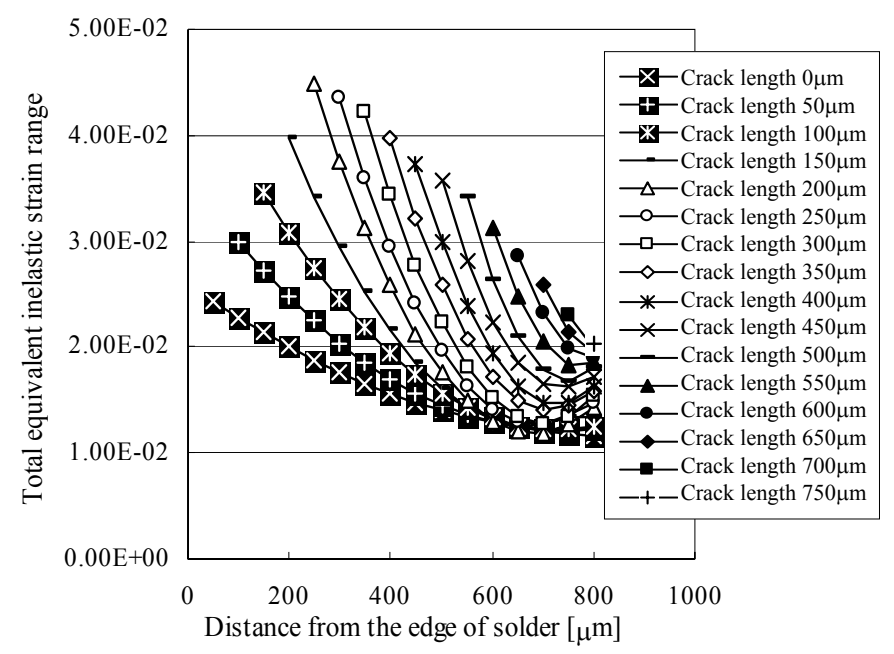

Fig. 4 Total equivalent inelastic strain range in each crack model 
Miner's rule is used to express the propagation process of the fatigue crack. By Miner's rule, the material receives damage only to the ratio of the number of repetitions to the fatigue life for each inelastic strain range. And if this ratio is the same, it is assumed to cause the damage of same level in the material. When total equivalent inelastic strain range $\Delta \varepsilon_{i n}$ is repeated $N_{i}$ times, the damage rate $\eta_{i}$ to fatigue life $N_{f i}$ of a certain level is defined as Equation (1)

$$
\eta_{i}=\frac{N_{i}}{N_{f i}}
$$

Then the total damage rate $\eta$ due to the all kinds of strain range $\Delta \varepsilon_{\text {in } i}(\mathrm{i}=1,2 \ldots \mathrm{n})$ can be expressed by equation (2)

$$
\eta=\sum_{i=1}^{n} \frac{N_{i}}{N_{f i}}
$$

When damage rate $\eta$ becomes 1.0 , the material reaches the fatigue life. And then, the crack is to propagate the next step. The fatigue life of each $50 \mu \mathrm{m}$ propagation with a strain range of $\Delta \varepsilon_{i n}$ are evaluated by Manson-Coffin's law with the total equivalent nonlinear strain as shown in Equation (3)

$$
N_{f}=A \times\left(\Delta \sin / \varepsilon_{0}\right)^{-h}
$$

Using Equation (2) and (3) for the results of showing in Fig. 4, the relation between the cyclic numbers and the crack length is obtained as shown in Fig. 5. At the same time, the failure life, that is defined, the fatigue life when solder joint is broken completely (when the crack propagates $800 \mu \mathrm{m}$ ) can be understood. The effectiveness of the prediction of the failure life by this technique has been confirmed by a past work [11].

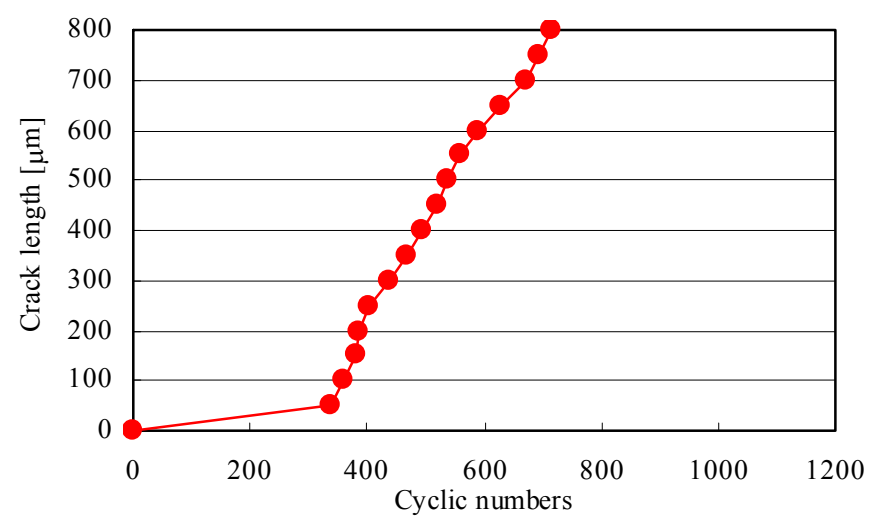

Fig. 5 Relation between the cyclic numbers and the crack length

\section{REliability EVAluation CONSIDERING THE} DISPERSION OF MAIN DESIGN FACTORS

It is understood that the failure lives of some electronic devices show large scatter in the thermal cycle test, even if their design is the same. The dispersion of shape, size and material properties of solder joints is thought as one of these reasons. In this section, the reliability evaluation considering the dispersion of main design factors is studied by using sensitivity analysis.

At first, main design factors whose dispersions are able to happen are selected as shown in Fig. 6, and Table 1 shows the range of the dispersion of these factors.

After that, an orthogonal table L18 is created by the DOE theory and 18 analytical models are made based on this table. The analytical model is shown in Fig. 7 as an example. The solder material is $\mathrm{Sn}-\mathrm{Ag}-\mathrm{Cu}$ lead-free solder. In this case of study, the failure life of solder joint is taken as the characteristic value by using fatigue crack propagation analysis. The detail condition of FEM analysis is stated as followings;

1) The temperature range is from $-40^{\circ} \mathrm{C}$ to $+125^{\circ} \mathrm{C}$ for the thermal load. The time of temperature change take 0.05 hour ( 3 minutes), and the dwelling time is 0.25 hour ( 15 minutes).

2) Based upon the symmetry of the chip structure, the quarter models are used in these analyses, and the symmetrical boundary conditions are subjected.

The failure lives are calculated using Equation (2) and (3) as described in the preceding section. The characteristic value can be expressed by an estimated equation. And the influence of each design factor to the failure life is calculated. The effective ratio of each design factor is shown in Table 2. From this result, it is clarified that the CTE of PCB and CTE of chip component show strong effect. When it comes to geometric factors, the thickness of solder layer under the electrode affects characteristic value the most. Moreover, the influence of each design factor is shown in Fig. 8. It can be identified easily how much influence each design factor has on the characteristic value from this Figure. And the trend of failure life can be known when each design factor changes its value.

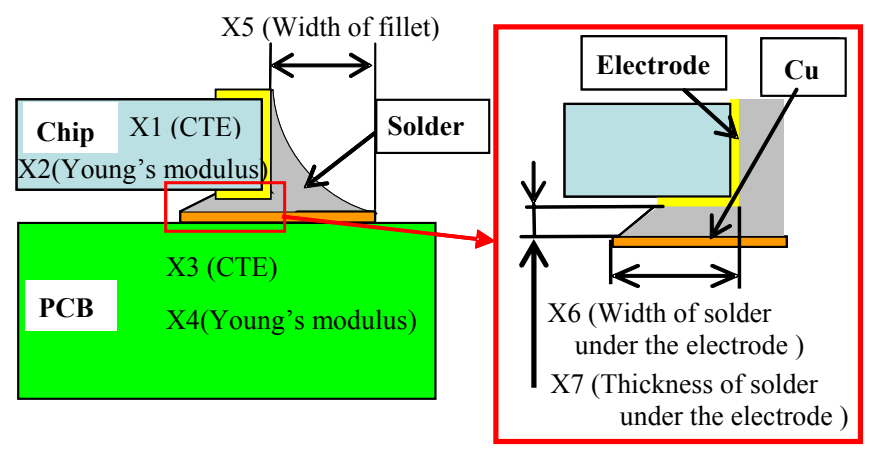

Fig. 6 Chip model and main design factors 
Table 1 Value levels

\begin{tabular}{|l|c|c|c|}
\hline \multicolumn{1}{|c|}{ Factor } & 1:Min & 2:Ave & 3:Max \\
\hline X1:CTE of Chip [ppm/K] & 2.8 & 3.5 & 4.2 \\
\hline X2:Young's modulus of Chip [GPa] & 128 & 160 & 192 \\
\hline X3:CTE of PCB [ppm/K] & 12 & 15 & 18 \\
\hline X4:Young's modulus of PCB $[\mathrm{GPa}]$ & 14.4 & 18 & 21.6 \\
\hline X5:Width of fillet $[\mu \mathrm{m}]$ & 600 & 750 & 900 \\
\hline X6: Width of solder under the electrode $[\mu \mathrm{m}]$ & 600 & 750 & 900 \\
\hline X7:Thickness of solder under the electrode $[\mu \mathrm{m}]$ & 10 & 30 & 50 \\
\hline
\end{tabular}

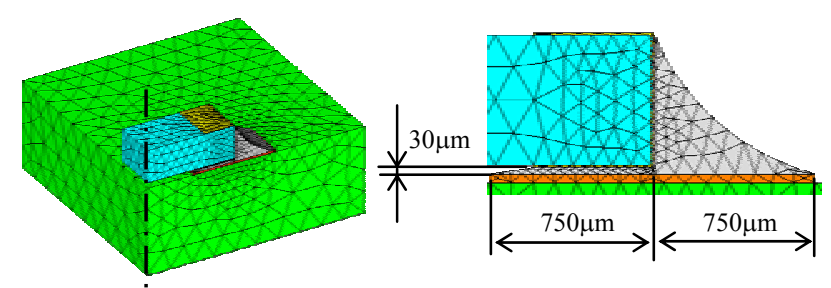

Fig. 7 Analytical model

Table 2 Influence of the main design factors

\begin{tabular}{|c|c|}
\hline Factor & Effective ratio \\
\hline X1:CTE of Chip & $9.96 \%$ \\
\hline X2:Young's modulus of Chip & $1.33 \%$ \\
\hline X3:CTE of PCB & $37.93 \%$ \\
\hline X4:Young's modulus of PCB & $3.89 \%$ \\
\hline X5:Width of fillet & $0.25 \%$ \\
\hline X6: Width of solder under the electrode & $11.36 \%$ \\
\hline X7:Thickness of solder under the electrode & $33.21 \%$ \\
\hline Error & $2.08 \%$ \\
\hline Total & $100.00 \%$ \\
\hline
\end{tabular}

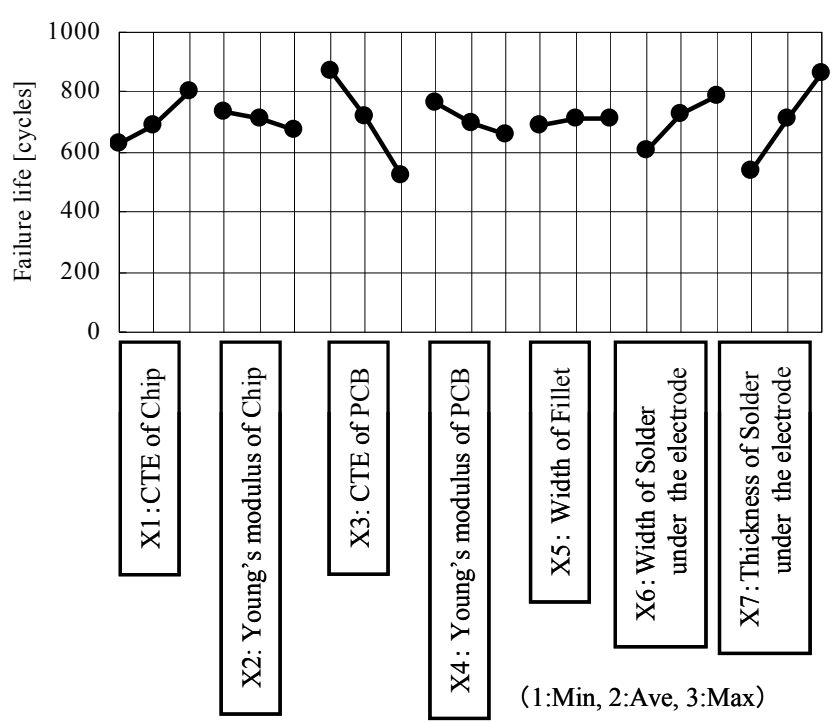

Fig. 8 Influence figure of main design factors
In order to clarify how much the dispersion of main design factors influences to the failure life, the following three models are prepared by using the result of Fig. 8 .

Model 1) The all design factors take the average value.

Model 2) The all design factors take the values which give the worst effect on the failure life.

Model 3) The all design factors take the values which give the best effect on the failure life.

The relation between the cyclic numbers and the crack length is shown in Fig. 9 and the failure lives are shown in Table 3. The failure life of Model 2 is 294 cycles and it decreased about $60 \%$ from that of Model 1. Meanwhile, that of Model 3 is 948 cycles and it increased about $90 \%$ from that of Model 1 . Thus, the dispersion of the failure life due to main effect of each design factors can be estimated from this result.

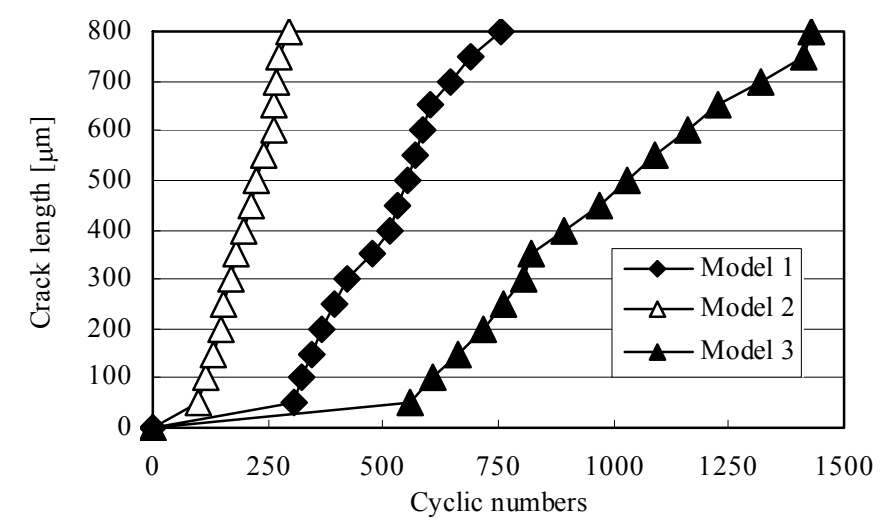

Fig. 9 Relation between the cyclic numbers and the crack length of Model $1 \sim$ Model3

Table 3 Failure lives of Model $1 \sim$ Model 3

\begin{tabular}{|c|c|c|c|}
\hline & Model 1 & Model 2 & Model 3 \\
\hline Falure life & 754 cycles & 294 cycles & 1430 cycles \\
\hline
\end{tabular}

\section{RELIABILITY EVALUATION CONSIDERING THE INTERACTION BETWEEN THE GEOMETRIC FACTORS}

A chip is mounted on the PCB with two sides of solder joints. However, the solder shapes can have a big scatter and be unbalanced. It is difficult to control the shapes and volume of the solder very accurately. Therefore, it cannot be bypassed as the main issue of the reliability evaluation in the solder joints. Based upon the structure symmetry, quarter models had been used in analysis. In this section, the reliability evaluation considering the structural asymmetry due to the unbalanced solder joints is studied.

To consider the structural asymmetry, a half model is used in this analysis (Model 4) as shown in Fig. 10. The following factors are set to express the structural asymmetry from among the main design factors discussed in the preceding section. 
X4) Width of fillet

X5) Width of solder layer under the electrode

X6) Thickness of solder layer under the electrode

Based on the results in preceding section, these factors of the right solder joint take the values which give the worst effect on the failure life and that of a left solder joint take the values which give the best effect. Moreover, the following two quarter models are prepared as an object of comparison.

Model 5) The geometric design factors (X5, X6, and $\mathrm{X} 7$ ) take the values which give the worst effect on the failure life.

Model 6) Those factors take the values which give the best effect on the failure life.

These models are shown in Fig. 13. The other design factors (X1 $\sim$ X4) take the average value in Model 4, Model 5 and Model 6. Fatigue crack propagation analyses are carried out by these models. The detail condition of FEM analysis is the same as the preceding section.

The failure lives are calculated using Equation (2) and (3). The relation between the cyclic numbers and the crack length is shown in Fig. 11 and the failure lives are shown in Table 4. From the results of Model 5 and Model 6, the dispersion due to geometric factors in the quarter model is 522 cycles $\sim 924$ cycles. If the right and left solder joint doesn't influence with each other, the dispersion due to unbalanced solder joints in the half model is sure not to change with these values. However, it is 406 cycles $\sim 1427$ cycles from the results of Model 4 and the dispersion is considerably growing compared with those of quarter models. These results clarify that the interaction between the geometric factors of solder joints greatly influences the dispersion of the failure life. Therefore, the reliability evaluation that considers not only the dispersion of main design factors but also the interaction between them is necessary.
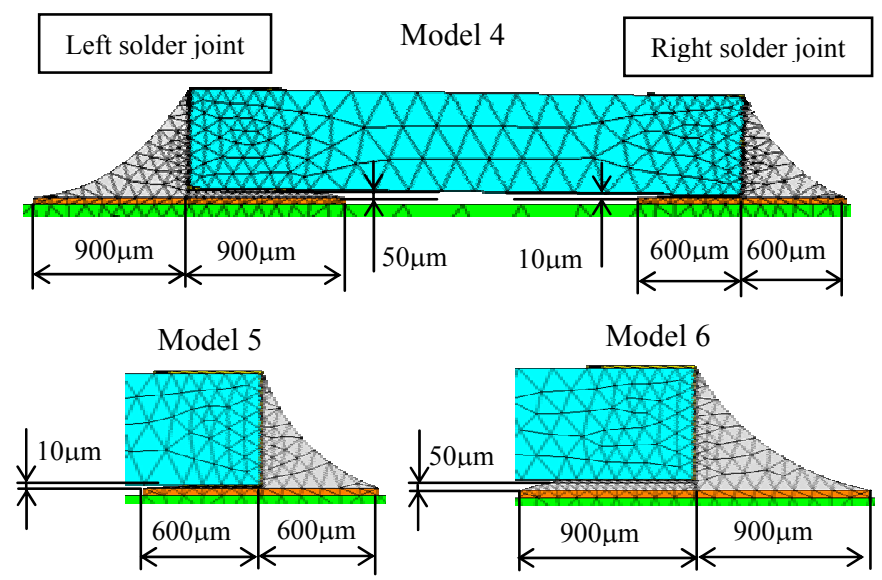

Fig. 10 Analytical model of Model $4 \sim$ Model 6

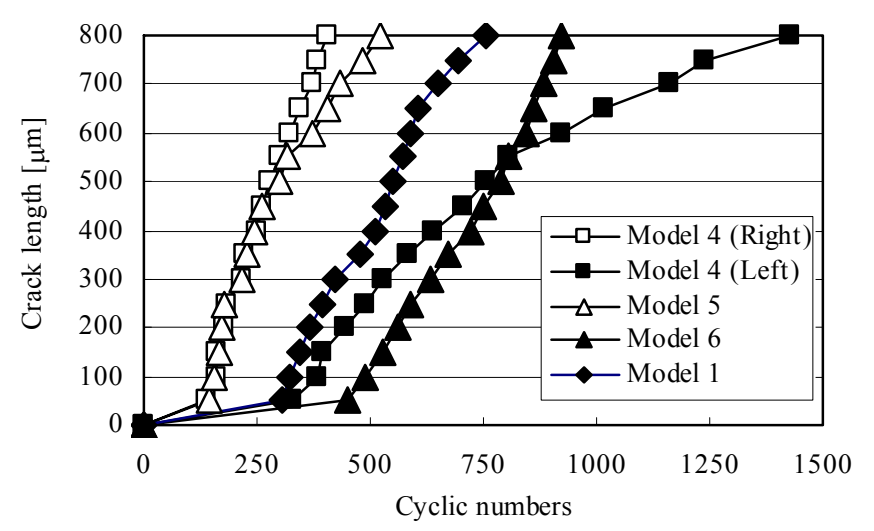

Fig. 11 Relation between the cyclic numbers and the crack length of Model $4 \sim$ Model 6 and Model 1

Table 4 Failure lives of Model $4 \sim$ Model 6

\begin{tabular}{|c|c|c|c|c|}
\hline \multirow{2}{*}{} & \multicolumn{2}{|c|}{ Model 4 } & \multirow{2}{*}{ Model 5 } & \multirow{2}{*}{ Model 6 } \\
\cline { 2 - 3 } & Right & Left & & \\
\hline Falure life & 406 cycles & 1427 cycles & 522 cycles & 924 cycles \\
\hline
\end{tabular}

\section{EFFECT OF INTERACTION FOR EACH GEOMETRIC FACTOR}

In this section, the effect of interaction for each geometric factor on failure life is studied.

The following three analytical models are prepared to examine the effect of the interaction for each factor.

Model 7) The model with different width of fillet

Model 8) The model with different width of solder layer under the electrode

Model 9) The model with different thickness of solder layer under the electrode

Fig. 12 shows these three analytical models. Fatigue crack propagation analyses are carried out for these models with the condition similar to the preceding section, and the failure lives are calculated. The relation between the cyclic numbers and the crack length is shown in Fig. 13 and the failure lives are shown in Table 5. From these results, it is confirmed that the interaction of the right and left thicknesses of solder layer under the electrodes greatly influence the failure life. Moreover, it turns out that the effect of the different width under the electrodes is also large. However, the effective ratio to the failure life of this factor is not so large when evaluating it by quarter models as shown in Table 2. The effective ratio of the width of solder layer under the electrode was $11.36 \%$. As a result, it is very important to evaluate the effect of each factor by including the interacting relation. Thus, a more advanced reliability evaluation can be carried out by considering interaction. 


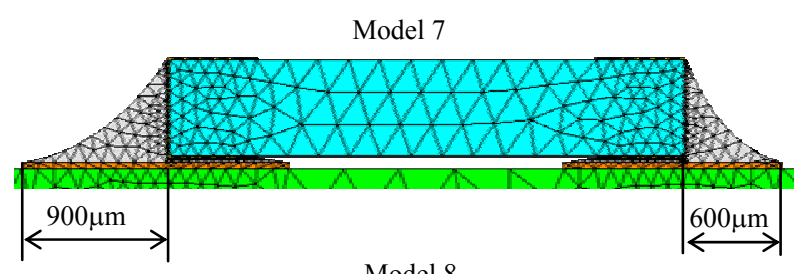

Model 8

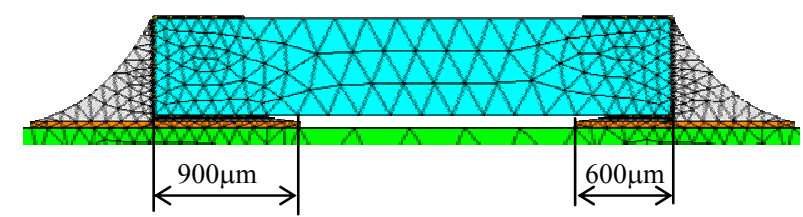

Model 9

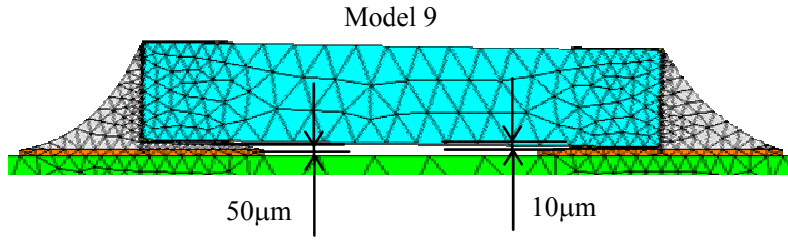

Fig. 12 Analytical models of Model $7 \sim$ Model 9

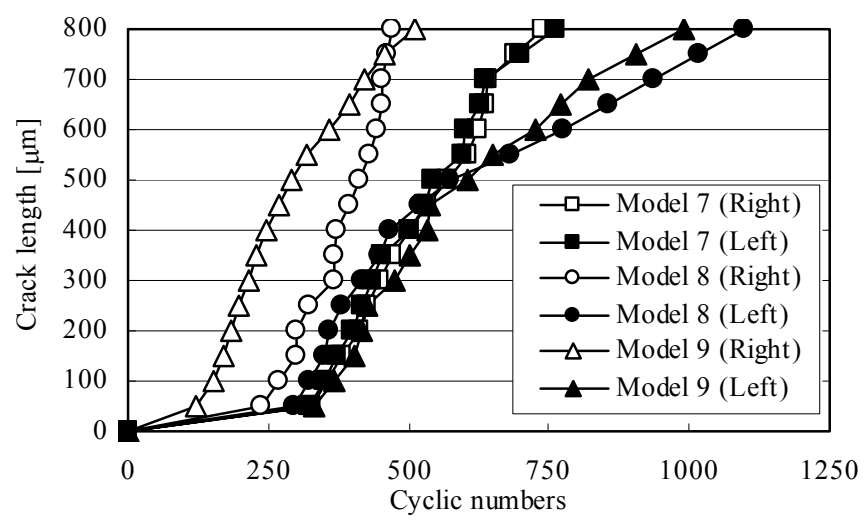

Fig. 13 Relation between the cyclic numbers and the crack length of Model $7 \sim$ Model 9

Table 5 Failure lives of Model $7 \sim$ Model 9

\begin{tabular}{|c|c|c|c|}
\hline & Model 7 & Model 8 & Model 9 \\
\hline Right & 739 cycles & 471 cycles & 509 cycles \\
\hline Left & 763 cycles & 1097 cycles & 990 cycles \\
\hline
\end{tabular}

\section{CONCLUSIONS}

1) The method of fatigue crack propagation analysis using a user subroutine was described. By using fatigue crack propagation analysis, not only crack initiation but also the process of crack propagation can be evaluated. Moreover, the fatigue life when solder joint is broken completely is calculated based on Miner's rule.

2) The reliability evaluation considering the dispersion of main design factors was studied. It was suggested that the dispersion of the failure life due to main design factors by the analytical results.
3) The reliability evaluation considering the interaction between the geometric factors of solder joints was studied. To express structural asymmetry due to the unbalanced solder joints, the half model was used in FEM analysis. From analytical result, it is clarified that the interaction greatly influences the dispersion of the failure life.

4) The interaction for each geometric factor of solder joints was examined. As for the factor that there was less influence in quarter models, it greatly influenced the failure life by considering interaction.

In this study, the failure life scatter of solder joint can be evaluated quantitatively by considering the dispersion of main design factors and the interaction between the geometric factors. It is possible to carry out more advanced reliability evaluation by using this technique.

\section{REFERENCES}

[1] Kitano M., Kumazawa W., Kawai S.: A New Evaluation Method for the Thermal Fatigue Strength of Solder Joints, ASME, Advances in Electronic Packaging EEP-vol. 1-1, 1992, 301.

[2] Mukai, M. Takahashi, H. Kawakami, T., Takahashi,K., Iwasaki, K and Kishimoto, K. "Mechanical Fatigue Tests of Solder Bumps", Advances in Electronic Packaging, EEP-Vol.26-1, pp. 449-455, 1999.

[3] Qiang YU, Masaki SHIRATORI, Shinya OHISHI.: Development and Application of the Fatigue Testing Machine for the Microstructure, JSME Annual Meeting, 1999, vol.3, pp.69-70

[4] Qiang YU, Masaki SHIRATORI.: Thermal Fatigue Reliability Assessment for Solder Joints of BGA Assembly, Proceeding of International Conference on Interpack'99, ASME, EEP-Vol. 26, No. 1, pp. 239-246, 1999.

[5] Tanie, H., Terasaki T and Naka, Y., "A New method for evaluating fatigue life of micro-solder joints in semiconductor structures", Proceedings of ASME InterPACK '05, pp. 1-7(CD-ROM:IPACK2005-73331), 2005.

[6] Mukai, M., Hirohata, K., Takahashi, H., Kawakami, T. and Takahashi, K., "Damage Path Simulation of Solder Joints in QFP", Proceedings of ASME InterPACK '05, pp. 1-6(CD-ROM:IPACK2005-73297), 2005.

[7] Manson, S.S.: International Journal of Fracture Mechanics, vol. 2, No. 1, pp. 327-363, 1966

[8] Miner, M. A. : J. Appl. Mech., 12 (1945), A159-A164

[9] Suganuma K, "Technology and practice handbook of lead-free solder" Realize company, 2000

[10] J.C. JIN, Q. YU, T. SHIBUTANI, H. ABE, M. SHIRATORI : The assessment of influence of design factors on the reliability of BGA solder joints, Key Engineering Materials, Vol.297-300, 2005, pp.1822-1827

[11] Qiang YU, Tadahiro SHIBUTANI, Jae-Chul JIN, Hirokazu ABE: Evaluation of Rupture Life in Solder Joints using Automatic Crack Propagation Analysis, Proceeding of The $18^{\text {th }}$ Computational Mechanics Conference, pp.181-182 